\title{
CARACTERIZAÇÃO DA PRODUÇÃO DE ETANOL COMBUSTÍVEL A PARTIR DA CANA- DE-AÇÚCAR EM PERNAMBUCO NO PERÍODO 1980-2012
}

\section{Resumo}

\author{
Eduarda Sales Braga ${ }^{1}$
} Almir Silveira Menelau ${ }^{2}$

A utilização de combustíveis fósseis, quase que de forma exclusiva, pela economia brasileira, tem provocado sérios impactos ambientais, que somente podem ser revertidos com a diversificação da matriz energética nacional. Uma das alternativas fundamentais na diversificação dessa matriz é o etanol, biocombustível obtido a partir da cana-de-açúcar. Diante desta potencialidade do etanol para o Brasil, e considerando a contribuição de Pernambuco para a produção nacional deste biocombustível, analisou-se a produção pernambucana de etanol, utilizando um modelo econométrico de função de produção (tipo Cobb Douglas). Para tanto, foram levantadas informações a partir de uma série histórica de dados que cobriu o período de 1980/2012. Os resultados obtidos com o modelo, com as elasticidades-preço da oferta e elasticidade cruzada entre preço de açúcar e produção de etanol, permitiram concluir que a produção de etanol está vinculada aos preços do açúcar, em que aumentos no preço do açúcar viabilizarão sua produção e reduzirá a produção de etanol combustível.

Palavras-chave: Biocombustível; Energia; Preços.

\section{CHARACTERIZATION OF FUEL ETHANOL PRODUCTION FROM SUGAR CANE IN PERNAMBUCO IN THE PERIOD 1980-2012.}

\section{Abstract}

The use of fossil fuels, almost exclusively, the Brazilian economy has caused serious environmental impacts, which can only be reversed with the diversification of the national energetic matrix.

\footnotetext{
Graduada em Economia (UFRPE). Mestrado em Administração e Desenvolvimento Rural (UFRPE). E-mail: eduardasbraga@yahoo.com.br

${ }^{2}$ Graduado em Agronomia (UFRPE). Mestrado em Economia Rural (UFV). Doutorado em Economia (UFPE). Professor da Universidade Federal Rural de Pernambuco (UFRPE). E-mail: almirmenelau@yahoo.com.br
} 
One of the fundamental alternative in the diversification of this matrix is ethanol, biofuel made from cane sugar. Given this potential of ethanol to Brazil, and considering the contribution of Pernambuco for domestic production of this biofuel, we analyzed the Pernambuco ethanol production, using the econometric model of production function (type Cobb Douglas). To this end, information was raised from a time series of data that covered the period from 1980/2012. The results obtained with the model, with price elasticities of supply and cross- price elasticity between sugar and ethanol production, was concluded that ethanol production is linked to sugar prices, in which the increases of the price of sugar will enable your production and will reduce the production of fuel ethanol.

Keywords: Biofuel; Energy; Prices.

\section{INTRODUÇÃO}

O crescimento da demanda mundial por etanol é motivada pelos interesses dos países procurarem opções para diminuírem as emissões de gases de efeito estufa, redução da dependência do petróleo e principalmente uma alternativa para a diversificação da sua matriz energética, principalmente tendo em vista o esgotamento das reservas de combustíveis fósseis.

A discussão sobre ações econômicas sustentáveis que reduzam os impactos ambientais vem sendo bastante debatidas nos últimos anos. O Protocolo de Kyoto iniciado em 1997, na cidade de Kyoto, no Japão, tem como objetivo firmar acordos internacionais para promover metas de redução de gases poluentes causadores do aquecimento global. No referido protocolo os países devem colaborar entre si na produção de bens e serviços a partir de processos menos impactantes ao meio ambiente. O protocolo sugere ações comuns, dentre elas o aumento no uso de fontes de energias limpas.

O Brasil também capitaneou recentemente discussões em nível global, a exemplo da conferência Rio +20 realizada em 2012, com o intuito de promover debates e ações de políticas sustentáveis, tornando assim uma preocupação mundial sobre a utilização de meios que diminuam a degradação ambiental.

Um assunto, repetidas vezes abordadas nas discussões sobre a sustentabilidade, é a utilização de fontes energéticas limpas, pois a energia é um dos pilares fundamentais para o desenvolvimento econômico e social de um país, influindo decisivamente na infraestrutura para os setores produtivos, geração 
de emprego e renda, qualidade de vida, e por se tratar de um setor estratégico para a nação. Além dessas questões, segundo Batalha e Buainain (2007) vários são os estudos que apontam o esgotamento das fontes de energia fóssil para os próximos anos, destacando a necessidade de buscar outras fontes alternativas. No entanto, os constantes conflitos políticos envolvendo os países do Oriente Médio, onde estão localizadas quase $80 \%$ das reservas comprovadas de petróleo no mundo, conferem instabilidade ao suprimento e aos preços do combustível, incentivando várias nações a reduzir a dependência em relação às importações do produto.

Tendo em vista o avanço da consciência ambiental, a diversificação da matriz energética e a necessidade de reduzir a dependência da utilização de petróleo, fonte de energia não renovável e de origem fóssil, impulsionaram-se estudos voltados para o desenvolvimento de novas alternativas na produção de combustíveis, como o etanol, que se tornou uma opção eficaz por ser uma fonte renovável originada de produtos vegetais. De acordo com Sampaio, Vital e Ramos (2011), o uso de biocombustíveis vem sendo estimulado com vários propósitos, entre os quais destacamse: a redução de emissões de gases de efeito estufa e a substituição do petróleo, devido tanto aos elevados preços do barril no mercado mundial como à busca de diminuição da dependência de combustível fóssil.

Além da sua relevância quanto às questões ambientais, a política de segurança energética é de grande importância, pois uma redução na oferta de petróleo pode paralisar as principais economias do mundo, o que torna considerável o papel do bioetanol não apenas no contexto de benefícios ambientais, mas também em sua contribuição para a matriz energética dos países.

O Brasil tem tradição na produção de bioetanol e possui uma vasta área onde pode ser cultivada a cana-de-açúcar, destacando-se como pioneiro na produção de etanol como combustível por deter condições vantajosas de clima, água e solo para a agricultura, e tendo considerável capital intelectual oriundo da tecnologia desenvolvida, que surgiu com o Proálcool, em 1975, devido a crise do petróleo em 1973. Segundo Safatle (2011), a agroenergia, sobretudo a produção de etanol a partir da cana-deaçúcar, constitui hoje o segmento econômico com maior capacidade de gerar, a um só tempo, uma multiplicidade de impactos virtuosos. A variedade de benefícios é enorme, a começar por colocar o país na vanguarda do processo de geração de energia alternativa em âmbito mundial. Quanto mais se avançar na produção do etanol e aumentar seu consumo em relação aos derivados de petróleo, tanto 
vamos estender seu horizonte temporal, expandindo a vida média de nossas reservas de petróleo.

A cana-de-açúcar apresenta-se como matéria-prima mais competitiva para a produção de etanol em termos de custos de produção. Seu cultivo no Brasil adveio com os primeiros colonizadores. Na época (século XVI), a área de maior significância no cultivo foi a Zona da Mata Pernambucana, e o Estado de Pernambuco passou a ser o pioneiro e o mais importante dos territórios da colônia na produção de açúcar, caracterizando este produto como a commodity de maior interesse no mercado internacional de produtos agrícolas. Para Barros et. al. (1998), a cana-de-açúcar estruturou os espaços físico, econômico e social da Zona da Mata, especializando a economia local e individualizando a sua sociedade no contexto regional e social.

Com efeito, o setor sucroenergético do país encontra-se em verdadeira evidência devido às alternativas energéticas renováveis que precisam ser encontradas a fim de dar continuidade ao desenvolvimento sem extinguir as já existentes.

Segundo o cenário descrito pelo Painel Intergovernamental de Mudanças Climáticas (IPCC) para os próximos 100 anos, as projeções sobre os impactos das mudanças climáticas pelo intenso uso de fontes não renováveis de energia indicam perda da biodiversidade, queda na produção agrícola, deslocamento de populações, aumento do nível do mar e intensificação de eventos extremos. Desta forma, tornam-se cada vez mais necessários estudos sobre alternativas que possibilitem um melhor entendimento sobre o complexo energético.

A utilização do etanol da cana-de-açúcar até então tem se mostrado a matéria prima adequada como fonte de energia limpa, sendo uma alternativa para o crescimento do Estado de Pernambuco, que já foi pioneiro na produção dessa commodity, proporcionando uma revitalização em seu mercado doméstico.

Diante disso, o objetivo deste trabalho é analisar a situação atual da produção de etanol proveniente da cana-de-açúcar em Pernambuco, bem como suas perspectivas e influências em sua produção.

\section{BIOCOMBUSTÍVEL: PANORAMA DA PRODUÇÃO DE CANA- DE-AÇÚCAR E ETANOL}

A liderança do país na produção de etanol combustível proveniente da cana-de-açúcar representa uma oportunidade 
estratégica em um cenário de crescente demanda mundial por fonte de energia limpa. A reformulação dos sistemas energéticos e a pressão para redução de emissão de carbono colocaram em destaque no foco internacional novamente o velho e conhecido álcool brasileiro. Uma previsível escassez de combustíveis fósseis em algum ponto futuro, o aumento de demanda por energia devido ao crescimento mundial e a preocupação crescente com a questão ambiental e com o aquecimento global têm levado os países a buscarem novas fontes de energia. Nesse contexto, uma das mais importantes iniciativas, com reconhecimento em escala mundial, é a produção de biocombustíveis, em especial o álcool (TÁVORA, 2011).

Existem diversos fatores favoráveis para a expansão da produção de etanol no Brasil, dentre eles as oscilações do preço dos barris de petróleo provocando incertezas no seu suprimento, o reconhecimento global da importância ambiental com a utilização do etanol combustível, seu custo de produção a partir da cana-deaçúcar é inferior comparado a outras matérias-primas.

De acordo com Leite et. al. (2009), uma ampliação significativa da produção de bioetanol combustível no Brasil poderia constituir um projeto nacional desenvolvimentista.

De fato, uma série de fatores pode favorecer essa hipótese: a escalada dos preços do petróleo, que melhora a competitividade do bioetanol face à gasolina; a redução das emissões de gases de efeitos estufa proporcionada pelo uso do bioetanol proveniente da cana-de-açúcar para substituir gasolina; a grande disponibilidade de terras aptas para o cultivo da cana no país (o que inclui a recuperação de áreas de pastos degradados), sem necessidade de avançar sobre os principais biomas naturais remanescentes, em particular Amazônia, Pantanal e Mata Atlântica. Sua elevada produtividade, em termos de energia de biomassa por unidade de área, apresentada pela cana-de-açúcar e que ainda pode ser melhorada consideravelmente com o incremento do aproveitamento energético do bagaço e da palha; a expectativa de relaxamento das barreiras protecionistas ao bioetanol nos países industrializados e a expansão da produção nos países do trópico úmido, o que pode facilitar a criação de um mercado internacional para o bioetanol combustível, tornando-o uma commodity; os benefícios socioeconômicos advindos do efeito multiplicador do crescimento do setor, em função de sua ligação com toda a cadeia produtiva da economia, trazendo impactos expressivos na geração de emprego e renda.

Porém, o mercado internacional de etanol combustível é incipiente, devido a dificuldades no seu fornecimento, falta de 
infraestrutura e barreiras comerciais protecionistas impostas pelos países importadores.

Tendo em vista que o consumo de biocombustível, no caso do etanol proveniente da cana-de-açúcar, gera benefícios ambientais e maior segurança na matriz energética brasileira, produzi-los significa desenvolvimento para o Estado de Pernambuco, bem como geração de emprego e renda.

Na figura 1 apresenta-se uma série histórica (1980-2012) da produção de cana-de-açúcar no Estado de Pernambuco. Pode-se constatar que o período de crescimento na produção foi na metade dos anos 80, período em que o preço internacional do petróleo atingiu valores elevados, esse desempenho somente foi retomado a partir do ano de 2003, com a introdução dos veículos flex. O gráfico também demonstra uma redução na produção de cana-de-açúcar em Pernambuco no ano de 1994, isso pode ser explicado devido ao período de estiagem que atingiu a safra de 1993/1994.

Nos períodos em que a oferta aumentou possivelmente 0 preço do açúcar decresceu. Caso isto tenha acontecido, a produção de etanol foi mais vantajosa. Se a oferta de açúcar se mantém, então o etanol permanece estável. Já com a oferta de açúcar reduzida é provável que o etanol reduza também. Isto traz a baila o conceito econômico de Elasticidade-preço da oferta, que mede a variação percentual da quantidade ofertada, dada uma variação percentual no preço do produto em questão.

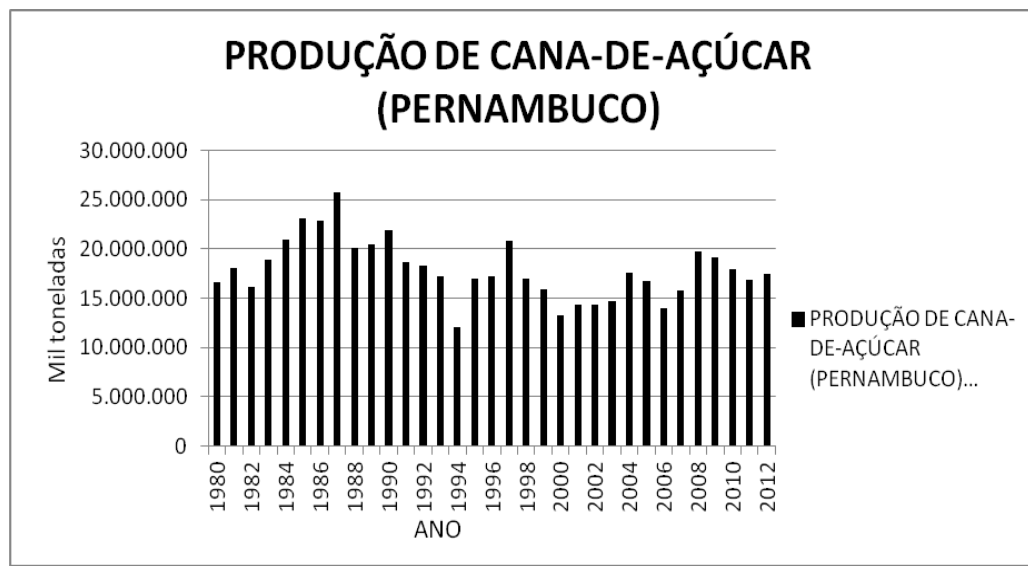

Figura 1 - Produção de cana-de-açúcar em Pernambuco em mil toneladas

Fonte: Sindaçúcar-PE. Elaboração própria. 
$\mathrm{Na}$ figura 2 apresenta-se o rendimento agrícola para o Estado de Pernambuco, sendo a produção total de cana-de-açúcar em toneladas e a área colhida em hectares. Do conjunto de dados apresentado percebe-se que não houve variações consideráveis para o rendimento no período estudado (1980 a 2012).

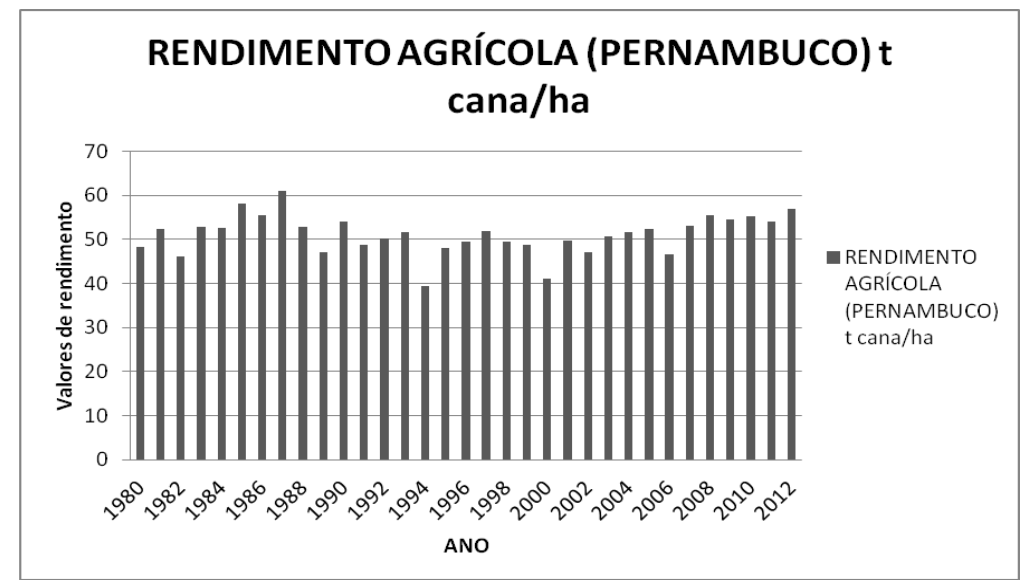

Figura 2 - Rendimento agrícola em Pernambuco em tonelada de cana/hectare

Fonte: Sindaçúcar-PE e ÚNICA. Elaboração própria.

Verifica-se na figura 3, as oscilações da produção de etanol para o Estado de Pernambuco. Podendo essas variações serem explicadas pelo preço do açúcar no mercado. Observa-se também o crescimento da produção no período pós-implantação do Proálcool. 


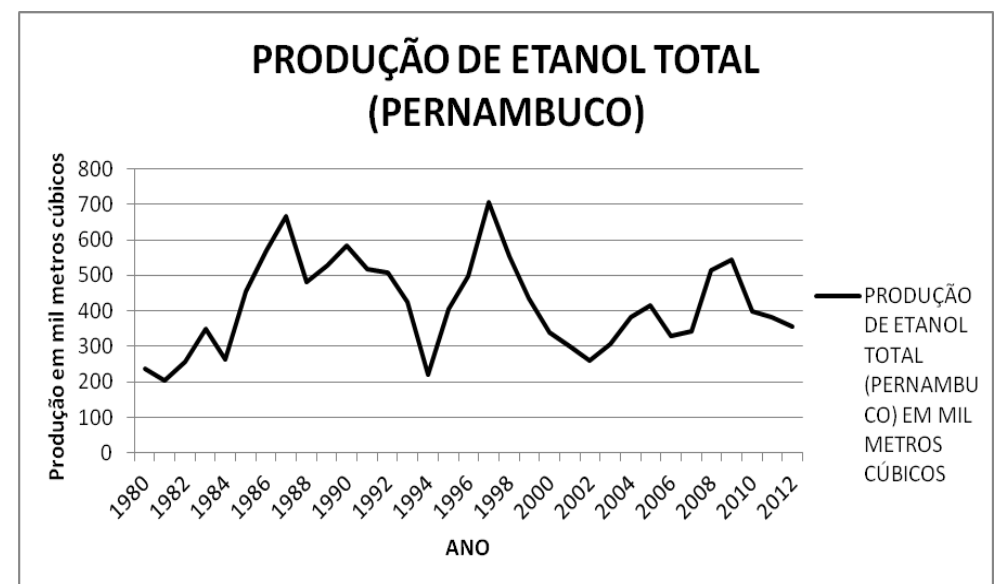

Figura 3 - Evolução da produção de etanol total em Pernambuco (Mil m³) Fonte: Sindaçúcar-PE e ÚNICA. Elaboração própria.

A evolução (Ver figura 4) dos preços do etanol, por sua vez, revela que tais preços foram maiores no período pós-implantação do Proálcool, mas já no final da década de 80 , o mercado entrou em declínio e a produção ficou estagnada, somente retomando o aumento a partir do ano de 2003, com o surgimento dos carros flexfluel (motores bicombustíveis).

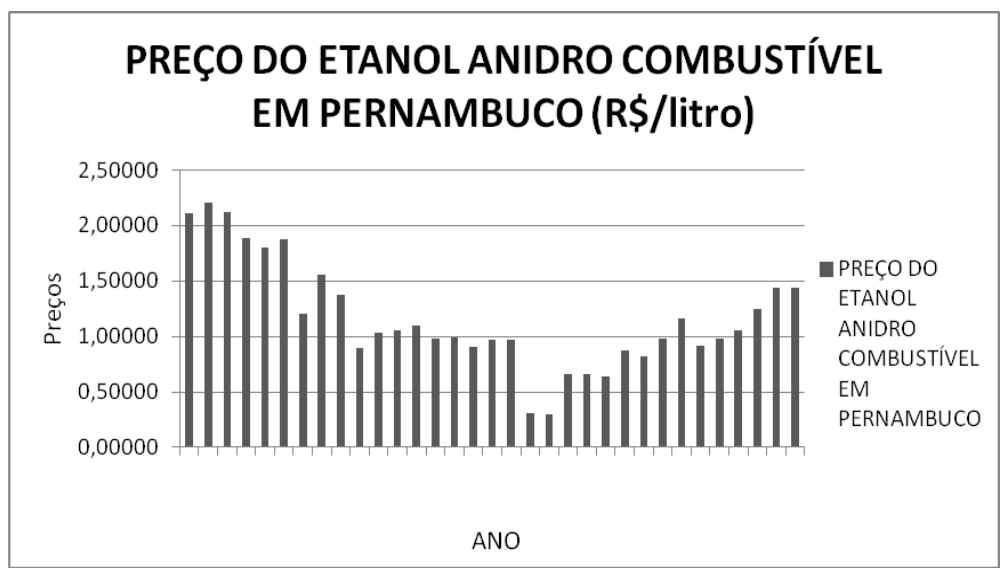

Figura 4 - Preço do etanol anidro combustível em Pernambuco (R\$/L) Fonte: Sindaçúcar-PE e ÚNICA. Elaboração própria. 
A partir da desregulamentação do setor sucroalcooleiro, a produção pernambucana de açúcar entrou em declínio, com a nova forma de organização do mercado, devido a concorrência, muitos produtores não conseguiram manter suas usinas e acabaram encerrando as suas atividades. Na década de 90 os baixos preços do açúcar nos mercados globais resultaram em uma menor produção de cana-de-açúcar.

Observa-se na figura 5 que no final dos anos 80 teve uma queda em seus preços devido ao aumento da produção de cana-deaçúcar. Já em 2010 houve uma elevação no preço do etanol, conforme visto na figura 4 e do açúcar (Figura 5). Algumas das suas causas foram: o baixo rendimento da produção, o aumento no preço do açúcar, que diminui a oferta interna de etanol, a crise de crédito de 2008/09 que fez com que muitos produtores de cana tomassem uma atitude conservadora em relação aos investimentos. Outro problema é que a estocagem de álcool paga preço de mercado, o que desestimulou a formação de estoques na entressafra.

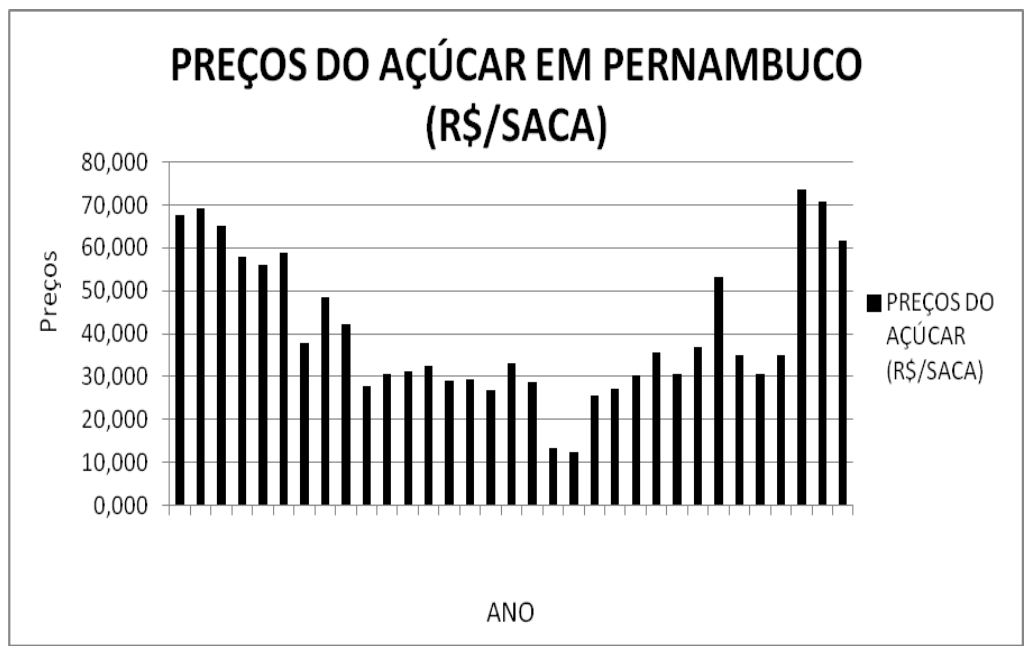

Figura 5 - Preços do açúcar em Pernambuco (R\$/saca)

Fonte: Sindaçúcar-PE e ÚNICA. Elaboração própria.

Dessa forma, a partir das informações coletadas da produção e dos preços foi elaborado um modelo explicativo da produção e cenários da produção de etanol no Estado de Pernambuco. 


\section{METODOLOGIA}

Para o ajustamento do modelo, procedeu-se como primeira etapa do trabalho uma pesquisa documental em fontes pertinentes ao tema do trabalho. Foi realizado também um levantamento de dados secundários junto ao Sindicato da Indústria de Açúcar e do Álcool no Estado de Pernambuco (Sindaçúcar-PE), da União da Indústria de Cana-de-açúcar (ÚNICA) e da Empresa de Consultoria de Etanol e Açúcar (DATAGRO), referente ao Estado de Pernambuco sobre área colhida, produção de cana-de-açúcar, produção de etanol anidro e hidratado, preços do etanol e preços do açúcar.

As informações coletadas na pesquisa foram referentes ao período de 1980-2012, devido existir maior disponibilidade de dados relativos ao período após a década de 80 . O suporte teórico utilizado neste trabalho baseia-se na Teoria da Produção, visto tal teoria permitiu analisar a produção de etanol para o Estado, utilizando as variáveis que a influenciam. Para Varian (2000), a função da produção pode ser definida como sendo a relação que indica a quantidade máxima que se pode obter de um produto, por unidade de tempo, a partir da utilização de uma determinada quantidade de fatores de produção.

Além disso, o estudo da produção através do ajustamento de funções de produção pode, para Garófalo e Carvalho (1990), apresentar grande importância, pois proporcionam as bases para a análise dos custos e da oferta dos bens produzidos. Normalmente, na análise microeconômica, é possível representar a função de produção da seguinte maneira:

$$
Q=f\left(x_{1}, x_{2}, x_{3}, \ldots, x_{n}\right)
$$

Onde $Q$ é a quantidade produzida do bem e $x_{1}, x_{2}, x_{3}, \ldots, x_{n}$ identificam as quantidades utilizadas de diversos fatores, respeitando o processo de produção mais eficiente escolhido.

O modelo estimado neste trabalho, conforma uma função de produção do tipo Cobb-Douglas, em virtude da facilidade de interpretação dos resultados e das boas qualidades estatísticas dessa especificação. Contudo a sua utilização apresenta algumas limitações em seu uso. Segundo Almeida (2005) suas principais limitações são as elasticidades de substituição unitárias entre os insumos. Essas limitações poderiam ser contornadas com a adoção 
de uma forma funcional mais flexível, tais como a forma logarítmica. Já para Nazareth e Guttierez (1975), seu aspecto pouco compacto não permite que a estrutura da economia e outras relações mais complexas intervenham.

Cobb e Douglas propuseram em seu artigo, publicado em 1928, para estimar a produção uma função apresentada da seguinte forma:

$$
Q=A K^{\beta 1} L^{\beta 2} \quad \beta_{1}+\beta_{2}=1
$$

Onde $Q$ representa o produto, enquanto $K$ e $L$ são os insumos considerados (capital e trabalho, respectivamente), o coeficiente $A$ é uma constante e $\beta_{1}$ e $\beta_{2}$ são parâmetros. Aplicando o logaritmo para ambos os lados da equação e chamando o termo constante de A, tem-se:

$$
\operatorname{LnQ}=\operatorname{Ln} A+\beta_{1} \operatorname{LnK}+\beta_{2} \operatorname{LnL}
$$

Neste modelo, a função Cobb-Douglas foi utilizada na sua forma logarítmica, onde a produção é função das variáveis capital e trabalho. Neste modelo o parâmetro A representa a constante e os parâmetros $\beta_{1}$ e $\beta_{2}$ representam as elasticidades da produção em relação ao capital e ao trabalho, respectivamente.

Para a estimação do modelo foi utilizado o software econométrico, Eviews.

Com isso, para o estabelecimento da produção de etanol em Pernambuco, foi estimada uma função de produção do tipo Cobb-Douglas $\left(Q=A K^{\beta 1} L^{\beta 2} M^{\beta 3}\right)$, na sua forma logarítmica:

$$
\log Q=\log A+\beta_{1} \log K+\beta_{2} \log L+\beta_{3} \log M
$$

Onde:

$Q=$ Produção de etanol total em mil metros cúbicos;

$\mathrm{K}=$ Rendimento agrícola da cana-de-açúcar expresso em t/ha;

$\mathrm{L}=$ Preço do açúcar em $\mathrm{R} \$ /$ saca $(50 \mathrm{Kg})$;

$\mathrm{M}=$ Preço do etanol anidro em $\mathrm{R} \$ / \mathrm{L}$. 


\section{RESULTADOS E DISCUSSÕES}

De acordo com o modelo ajustado constatou-se (Tabela 1) que a produção de etanol varia negativamente com o preço de açúcar. O coeficiente da variável rendimento agrícola indica que a variação de $1 \%$ no rendimento agrícola significa um acréscimo em torno de 1,42\% na variação percentual da produção de álcool. Rejeita-se a hipótese nula, a um nível de significância de 1\%. Para o coeficiente da variável preço do açúcar, o modelo indica que a variação de $1 \%$ no preço, significa uma redução de $0,56 \%$ na produção de álcool. Com isso, rejeita-se também a hipótese nula, a um nível de significância de $5 \%$. Portanto admitimos que estas duas variáveis sejam significantes para explicar a produção de etanol.

Já para o coeficiente da variável preço do etanol anidro, a um índice de significância de 5\%, não rejeitou a hipótese nula, logo esta variável não apresenta influência no modelo analisado.

Em virtude do preço do açúcar ser uma variável significativa na produção de etanol, pois o açúcar se destina em grande parte à exportação, a elevação dos preços internacionais do produto favorece a produção de açúcar e, em consequência acarreta redução na produção de etanol. Por outro lado, visto a produção do combustível atender principalmente o mercado interno, seu preço sofre forte influência do preço do petróleo.

Tabela 1 - Modelo para a Produção de Etanol Total em Pernambuco.

\begin{tabular}{|c|c|c|c|}
\hline \multicolumn{4}{|c|}{ LOG (PRODUÇÃO DE ETANOL TOTAL) } \\
\hline VARIÁVEL & $\begin{array}{l}\text { COEFICIEN } \\
\text { TE }\end{array}$ & $\begin{array}{r}\text { DESVIO } \\
\text { PADRÃO } \\
\end{array}$ & PROB. \\
\hline C & 2,438757 & 1,927501 & $\begin{array}{l}0,2166 \\
0,0015\end{array}$ \\
\hline LOG (RENDIMENTO AGRÍCOLA) & 1,416488 & 0,401518 & \\
\hline $\begin{array}{l}\text { LOG (PREÇOS DO AÇÚCAR) } \\
\text { LOG (PREÇOS DO ETANOL }\end{array}$ & $-0,558544$ & 0,271085 & \\
\hline ANIDRO) & 0,409617 & 0,285323 & 0,1626 \\
\hline \multicolumn{4}{|l|}{$R^{2}=0.639876$} \\
\hline Durbin-Watson $=1.777511$ & & & \\
\hline
\end{tabular}

Fonte: Elaborado pela autora,

Eviews.

* Significância de 1\%

** Significância de 5\% 
A partir do estudo sobre a relação dos preços de comercialização do setor sucroalcooleiro realizado por Shikida (2007), foi constatado que as ofertas de açúcar e álcool paranaenses podem ser expressas a partir de uma modelagem econométrica. $\mathrm{O}$ autor encontrou que a quantidade ofertada de açúcar variou inversamente ao preço do etanol, assim como a quantidade ofertada de etanol variou inversamente ao preço do açúcar, mas esta última relação não foi significativa estatisticamente. Concluiu o referido autor que o dinamismo da agroindústria canavieira do estado do Paraná tem sido consequente da oferta de açúcar, sendo a oferta de álcool mais residual (comparativamente à produção de açúcar).

Considera-se que a produção de etanol em Pernambuco acha-se vinculada a produção de açúcar, conforme visto no modelo ajustado, a alteração de $1 \%$ no preço do açúcar condiciona uma redução de $0,56 \%$ na produção de etanol.

A Elasticidade cruzada entre preço do açúcar e quantidade de etanol corroborou com o modelo, em que efeitos de mudanças dos preços sobre as quantidades de equilíbrio podem ser analisados. De fato ao representar à sensibilidade da variável quantidade ofertada de etanol em relação ao preço do açúcar representa um indicador importante. Onde:

$$
\mathcal{E}={\frac{\Delta \mathrm{Q} \text { etanol }}{\Delta \mathrm{P}_{\text {açúcar }}}}_{\mathrm{Q}} \frac{\mathrm{Po}_{\text {açúcar }}}{\mathrm{Q}_{\text {etanol }}}
$$

A relação entre a alteração do preço de açúcar e a quantidade de álcool (elasticidade cruzada) representou $46 \%$ da dinâmica de produção de etanol em Pernambuco do período analisado (1980 a 2012). Além disso, o comportamento da oferta de etanol variou inversamente com a alteração do preço do açúcar. $\mathrm{Na}$ medida em que o preço do açúcar evoluiu positivamente a quantidade de etanol diminuiu, porém reduziu menos do que o percentual de acréscimo no preço do etanol, pois a elasticidade cruzada mostrou-se em $46 \%$ do período inelástica.

Os valores representados na figura 6 indicam por um lado que a oferta foi elástica em um subperíodo (a variação percentual de decréscimo na sua produção foi maior do que a variação percentual de acréscimo no preço). Por outro lado, em outro subperíodo, encontrou-se a produção variando positivamente com o preço do açúcar, porém em menor proporção que este. Isto ocorreu, possivelmente, devido a dinâmica dos preços internacionais do 
açúcar "vis-à-vis" a dinâmica dos preços de etanol que, por sua vez, é também afetada pela dinâmica dos preços do petróleo.

A figura também demonstra uma considerável redução em sua elasticidade cruzada no ano de 1994, o que pode ser explicado pela diminuição na produção de etanol devido ao período de estiagem na safra de 1993/1994 da cana-de-açúcar.

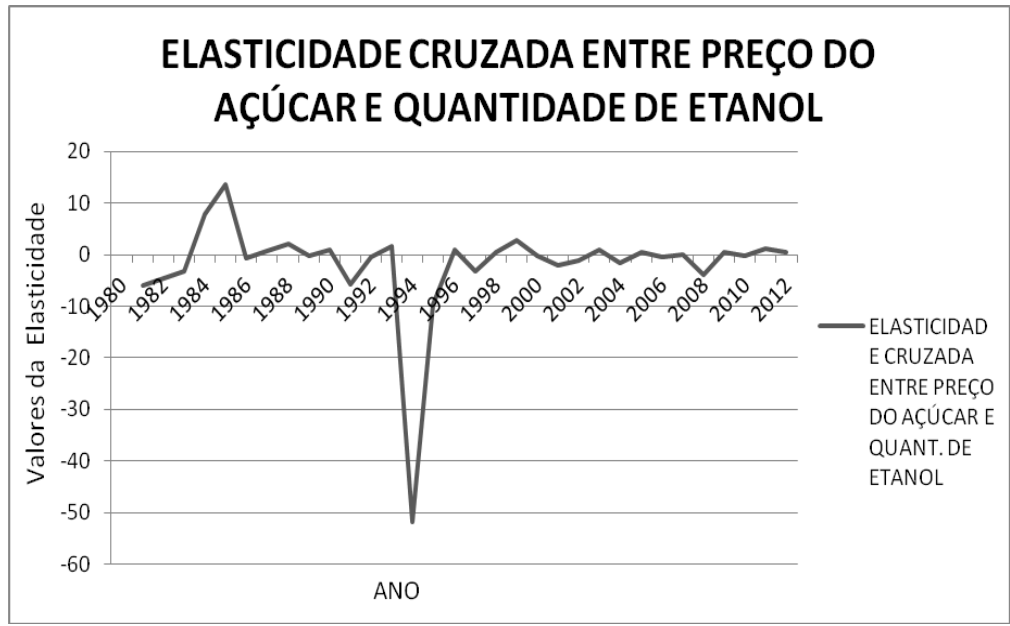

Figura 6 - Elasticidade Cruzada entre Preço do açúcar e quantidade de etanol para Pernambuco

Fonte: Elaboração própria a partir de dados do Sindaçúcar-PE e ÚNICA.

A elasticidade preço da oferta de etanol no período em análise demonstra que a inclinação da curva de oferta do produto é positiva, ou seja, o aumento (a diminuição) do preço causa o aumento (a diminuição) da quantidade oferecida. O preço e a quantidade variam na mesma direção.

Conforme constata-se na figura 7, a Elasticidade-preço da oferta comportou-se conforme identificado no modelo econométrico para explicar a oferta de etanol. Em $63 \%$ do período a oferta variou mais percentualmente do que o preço, confirmando ser a oferta de etanol preço-elástica. Ressalta-se, contudo, que no restante do período a elasticidade comportou-se de forma diferente (preçoinelástica). Isto aconteceu, provavelmente, por conta da variação do preço do açúcar, fenômeno que foi detectado pela elasticidade-preço cruzada (entre o preço de açúcar e a oferta de etanol), ou seja, mais uma vez confirmou-se a assertiva do modelo especificado ajustado. 
Comparando-se a elasticidade de oferta do açúcar com a elasticidade de oferta do etanol vê-se claramente que o crescimento da elasticidade do primeiro, implica em decrescimento da elasticidade do segundo. Isto indica que o crescimento da oferta de etanol se relaciona efetivamente com o preço do açúcar e não com o preço do etanol.

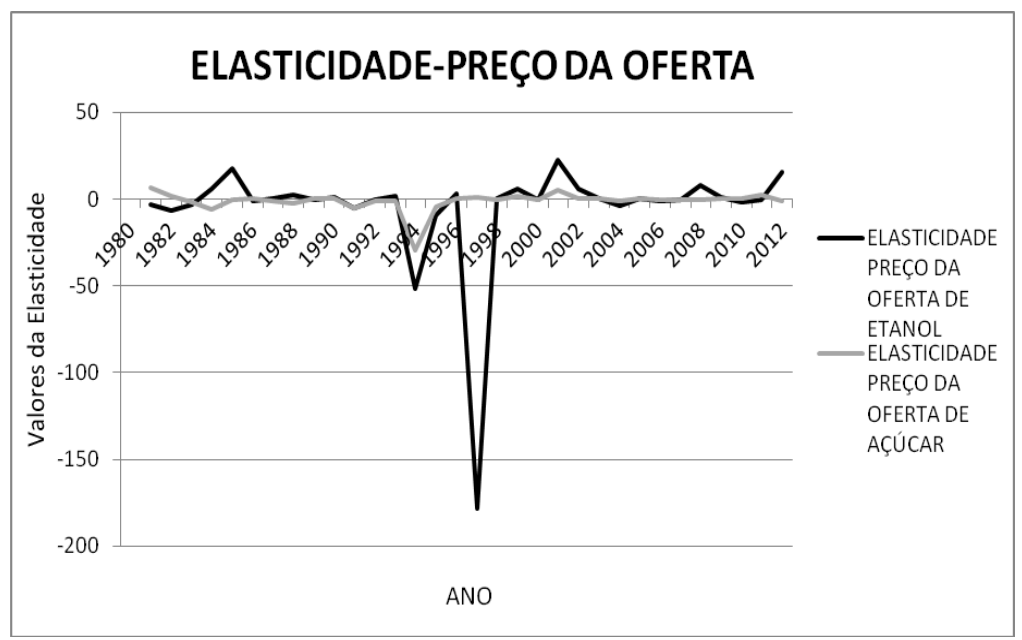

Figura 7 - Elasticidade-preço da oferta de etanol e açúcar para Pernambuco.

Fonte: Elaboração própria a partir de dados do Sindaçúcar-PE e ÚNICA.

\section{CONCLUSÕES}

Neste trabalho estimou-se um modelo incluindo as variáveis preço do açúcar, preço do etanol e rendimento agrícola, e sua relação com a produção de etanol combustível, através de uma série histórica relativa ao período de 1980 a 2012. O objetivo do ajustamento foi identificar que variáveis influenciam positiva ou negativamente a produção de etanol no Estado de Pernambuco.

Também procurou-se comparar as informações obtidas no modelo de produção de etanol para o Estado com os conceitos da microeconomia, utilizando os conceitos de elasticidade ponto, e elasticidades cruzadas entre preço do açúcar e quantidade de etanol e a elasticidade-oferta do açúcar e do etanol para Pernambuco. 
Os resultados das análises mostraram que a produção de etanol apresenta dependência com o preço do açúcar, e que maiores valores no preço do açúcar, levam produtores a terem mais interesse em produzir açúcar ao invés de etanol. O mesmo aconteceu com reduções no preço do açúcar visto que esta ocorrência viabiliza o aumento da produção de etanol. Essa dinâmica foi corroborada com os valores de elasticidades cruzadas entre preço do açúcar e quantidade de etanol, bem como as elasticidades de oferta do açúcar e etanol, demonstrando que quando o preço do açúcar evolui positivamente, acarreta uma redução da quantidade produzida de etanol.

Entretanto, ressalta-se que o aumento no volume de produção do etanol combustível, também foi afetado por políticas públicas de mercado, como a criação do Proálcool e a introdução dos automóveis bicombustíveis.

A ampliação da produção de etanol combustível poderá constituir um projeto nacional de crescimento, tendo como base a melhoria da competitividade do etanol em relação à gasolina, reduzindo a dependência desse combustível fóssil, a redução das emissões de gases de efeito estufa e aumento da produtividade em termos de energia gerada, sendo primordial para segurança energética nacional.

Desta forma, sugere-se a necessidade de uma ação coordenada e planejada entre o setor público e privado, tendo em vista a importância da cana-de-açúcar, pois é a partir dela que se obtêm dois produtos fundamentas para a economia brasileira: o açúcar e o etanol. Este primeiro volta-se tanto para o mercado interno quanto externo, já o segundo ainda é mais utilizado principalmente para abastecimento do mercado doméstico, porém com perspectivas de aumento de sua produção devido ao entendimento da importância de sua produção, visto que questões energéticas, como o avanço do etanol combustível, estão relacionadas com a segurança do Estado.

A expansão desse mercado significa oportunidades de desenvolvimento econômico e social para Pernambuco, bem como a sua importância estratégica para a soberania nacional, à medida que se desenvolve uma matriz energética menos poluente, renovável, diversificada e própria. 


\section{REFERÊNCIAS}

ALMEIDA, E. S. Função de produção agropecuária espacial. XLIII CONGRESSO DA SOBER "Instituições, Eficiência, Gestão e Contratos no Sistema Agroindustrial” ESALQ/USP, 2005.

BARROS, $\mathrm{H}$. et al. Agricultura de Pernambuco: uma visão de futuro. Secretaria de Agricultura. Universidade Federal Rural de Pernambuco, 131 p, 1998.

BUAINAIN, A. M.; BATALHA, M.O (Coord.). Cadeia Produtiva da agroenergia. Ministério da Cultura, Pecuária e Abastecimento, Secretaria de Política Agrícola, Instituto Interamericano de Cooperação para a agricultura. Série Agronegócios. Brasília: IICA: MAPA/SPA, v. 3, 112p, 2007.

COBB, C. W. e DOUGLAS, P. H. A Theory of Production. American Economic Association, pp. 139-165, 1928.

DATAGRO. Empresa de Consultoria de Etanol e Açúcar. Acompanhamento e comparativos de produção de cana-deaçúcar, açúcar e etanol. Acessado em 25/05/13. Disponível em: http://www.datagro.com.br/secao/91/norte-nordeste

GARÓFALO, G. de L.; CARVALHO, L. C. P. Teoria Microeconômica. São Paulo, SP. Editora Atlas, 2ª ed, 573 p, 1986.

IPCC. Quarto Relatório (AR4). Grupo de Trabalho I (WGI), 2007.

LEITE, R. C; CORTEZ, L. A. B. O Etanol Combustível no Brasil, 2008.

NAZARETH J. M.; GUTTIEREZ C. Análise Social. Os modelos macroeconômicos de crescimento e o crescimento demográfico. Segunda Série, Vol. 11, No. 42/43, p. 336-364, 1975.

SAFATLE, F. N. A Economia Política do Etanol: A democratização da agroenergia e o impacto na mudança do modelo econômico. São Paulo, SP: Editora Alameda, 296p, 2011.

SAMPAIO, Y. D. S. B; VITAL, T. W; RAMOS, G. Biocombustíveis: quatro questões sobre seu futuro. Artigo publicado na Sociedade Brasileira de Economia, Administração e Sociologia Rural, SOBER, 2011.

SHIKIDA, P. F. A., ALVES, L. R. A., SOUZA, E. C., CARVALHEIRO, E. M. Uma análise econométrica preliminar das ofertas de 
açúcar e álcool paranaenses. Rev. de Economia Agrícola, São Paulo, v. 54, n. 1, p. 21-32, jan./jun. 2007.

SINDAÇÚCAR. Sindicato da Indústria do Açúcar e do Álcool no Estado de Pernambuco. Notícias-Estatísticas. Acessado em 20/06/2012. Disponível em: http://www.sindacucar.com.br/noticias_estatisticas.html.

TÁVORA, F. L. História e Economia dos Biocombustíveis no Brasil. Centro de Estudo da Consultoria do Senado. Brasília, DF, 78p (Texto para Discussão, 89), 2011.

UNICA. União da Indústria de cana-de-açúcar. Unicadata. Acessado em 09/07/2012. Disponível em: http://www.unicadata.com.br.

VARIAN. H. R. Microeconomia. Princípios básicos, uma abordagem moderna. Rio de janeiro, RJ. Editora Campus, 2000. 